\title{
Deus e Darwin nos tribunais: a controvérsia criação- evolução na arena jurídica dos tribunais estadunidenses
}

\author{
God and Darwin in the courts: the controversial creation-evolution in the \\ legal arena of the US courts
}

Roney de Seixas Andrade *

\begin{abstract}
Resumo
O objetivo deste artigo é analisar os principais casos jurídicos das cortes estaduais e federais dos Estados Unidos que envolveram a histórica e controversa disputa entre criacionistas e evolucionistas naquele país. Desde a aprovação das leis antievolucionistas na década de 1920 até a disputa judicial em torno da Teoria do Design Inteligente em Dover, 2005, passando pelas leis que buscavam garantir o tratamento balanceado entre o ensino da perspectiva evolucionista darwinista e da ciência da criação nas escolas e universidades públicas estadunidenses na década de 1980, observa-se, por um lado, o deslocamento do ponto de aplicação da religião a qual paulatinamente foi perdendo para a ciência seu lugar proeminente como exclusiva reserva de sentido válida para explicar a realidade das coisas, e, por outro, uma tendência de politização da religião bem como uma tendência de judicialização nas relações e nas articulações entre religião e ciência especialmente no âmbito da cultura pública norte-americana.
\end{abstract}

Palavras-chave: religião; ciência; criacionismo; evolucionismo; Estados Unidos.

\begin{abstract}
The purpose of this article is to analyze the main legal cases of the United States federal and state courts that involved the historic and controversial dispute between creationists and evolutionists in that country. From the passage of antievolutionary laws in the 1920s to the legal dispute over Dover's Intelligent Design Theory in 2005, through laws that sought to ensure a balanced treatment of Darwinian evolutionary education and the science of creation in schools and American public universities in the 1980s, it's observed the displacement of the point of application of religion which gradually lost to science its prominent place as exclusive reserve of valid meaning to explain the reality of things, on the other, a tendency to politicize religion as well as a tendency to judicialize relations and articulations between religion and science, especially within the framework of American public culture.
\end{abstract}

Keywords: religion; science; creationism; evolutionism; United States.

Artigo submetido em 21 de abril de 2018 e aprovado em 28 de abril de 2019.

* Doutor em Ciência da Religião pela UFJF. Professor no Departamento de Ciências Humanas e Sociais Aplicadas da Faculdade Sul Fluminense. País de origem: Brasil. E-mail: drroneyandrade@gmail.com 


\section{Introdução}

No cenário da cultura pública norte-americana, a teoria evolucionista darwinista atuou e ainda continua atuando como um dos instrumentos de desintegração do tácito acordo cultural em torno do teísmo bíblico. Como sabemos a teoria elaborada por Darwin abalou diretamente não apenas a concepção bíblica da criação, mas também a compreensão cristã acerca da natureza e do destino humano, bem como a compreensão do teísmo mesmo. De fato, o forte impacto do darwinismo nos EUA foi notoriamente constado nas palavras de Charles Eliot, professor da Universidade de Harvard, que em 1909 conclui, acertadamente, que a partir do darwinismo "os cristãos não teriam o monopólio da verdade, pois as ideias dos cientistas, dos secularistas ou dos que professavam outra fé seriam igualmente válidas" (ELIOT, 1909, p. 20).

Diante dessa constatação, no início do século XX, seguimentos evangélicos norte-americanos que se viam como fundamentalistas - por acreditarem que "o darwinismo levaria os jovens a perderem a fé em Deus, na Bíblia e em doutrinas fundamentais do cristianismo", bem como por conceberem a teoria da evolução como algo incompatível com a "moralidade", com a "decência" e com a "sobrevivência da civilização" (ARMSTRONG, 2009, p. 243) - reagiram ao darwinismo e a todo tipo de secularismo moderno através de uma série de textos que constituíram uma coleção de volumes intitulados The Fundamentals: $A$ Testimony to the Truth. ${ }^{1}$ Nesta coleção encontram-se as afirmações destes fundamentos através dos quais os fundamentalistas expressaram sua oposição contra as transformações provocadas nas instituições religiosas e na própria religião pela dinâmica mesmo da modernidade. Simultaneamente, essa coleção aponta para uma tendência de politização da religião, sempre mais crescente nos EUA, desde o momento em que os adeptos dos Fundamentals, cada vez mais organizados, passaram a exigir do estado, por exemplo, a implementação de políticas públicas de ensino consoantes com os ensinamentos da Bíblia.

${ }^{1}$ Sobre a reação dos fundamentalistas ao darwinismo e ao secularismo, ver Martin (1996, p. 11-13). 
É justamente no âmbito deste cenário de conflito cultural que propomos analisar, no presente artigo, os três principais momentos da turbulenta história da controvérsia criação-evolução nos quais estes debates foram levados aos tribunais estaduais ou federais dos Estados Unidos. Assim sendo, analisaremos em primeiro lugar a emergência e a queda das leis antievolucionistas na década de 1920. Em seguida, analisaremos o surgimento da assim chamada "Ciência da Criação" e a lei que concedeu tratamento balanceado à ciência da criação e a teoria evolutiva darwinista em 1981 e sua posterior queda no ano de 1987. E por último, trataremos da disputa judicial em torno da Teoria do Design Inteligente em Dover, na primeira década do presente século.

Além disso, considerando essas análises em conjunto, poderemos também perceber que as disputas jurídicas entre criacionistas e evolucionistas travadas nos referidos casos, apontam para duas questões importantes nas relações entre religião e ciência ao longo dessas décadas. A primeira, de caráter epistemológico, referente ao processo de deslocamento do ponto de aplicação da religião, ou seja, o fato da religião perder seu lugar de exclusiva reserva de sentido válida a orientar a vida dos indivíduos e a explicar a realidade das coisas. E, a segunda, de caráter ético-jurídico, acerca da tendência de politização cada vez mais crescente da religião e da judicialização dos conflitos e tensões que envolveram a disputa entre as concepções criacionistas e evolucionistas nos EUA.

\section{A emergência e a queda das leis antievolucionistas}

A década de 1920 foi aquela em que o político democrata e presbiteriano William Jennings Bryan promoveu uma "cruzada" contra o ensino da teoria da evolução nas escolas e faculdades norte-americanas. Em cerca de vinte estados federados, surgiram projetos de lei proibindo o ensino da teoria darwiniana. Os estados de Flórida, Mississipi, Oklahoma, Lousiana e Arkansas, dentre outros, promoveram leis contra o ensino do evolucionismo. Em Oklahoma, o legislativo do estado aprovou a primeira lei antievolucionista dos Estados Unidos em março de 1923. Essa lei proibia que livros escolares veiculassem ideias evolucionistas. No 
mesmo ano, o estado da Flórida aprovou uma resolução, redigida pelo próprio Bryan, que proibia o ensino da evolução como fato empírico (PRIEST, 1999, p. 59). Por sua vez, o estado do Tennesse foi aquele onde se estabeleceu a lei mais severa, o Butler Act, de 1925, que transformou em infrator "qualquer professor em qualquer universidade ou escola pública do estado que ensinar alguma teoria que negue a história da criação divina do homem conforme ensinado na Bíblia e insistir que o homem descende de alguma espécie de animal” (MARTIN, 1996, p. 14).

Segundo o Ato Público do Estado do Tennesse aprovado pela $64^{\mathrm{a}}$ Assembleia Geral em 13 de março de 1925, "ficou proibido o ensino da teoria da evolução em todas as universidades e todas as escolas públicas do Tennesse, que são sustentadas no todo ou em parte pelos fundos da escola pública do Estado, sendo previstas sansões para as violações do mesmo". Neste mesmo Ato foi decretado pela Assembleia Geraldo Estado do Tennesse, que "será considerado infrator qualquer professor em qualquer universidade ou em toda escola pública do Estado, que são sustentadas no todo ou em parte pelos fundos da escola pública do Estado, ensinar qualquer teoria que negue a história da Criação Divina do homem como ensinada na Bíblia para ensinar que o homem descende de uma ordem inferior de animais”. Além disso, como já dissemos, ficou também decretado que "qualquer professor considerado culpado de violar o presente Ato, será considerado contraventor e após a condenação, será multado em não menos que cem $(\$ 100,00)$ e não mais que quinhentos dólares $(\$ 500,00)$ por cada infração". ${ }^{2}$

Foi exatamente no Tennesse que o jovem professor John Scopes, da pequena cidade de Dayton, confessou ter infringido esta lei numa de suas aulas de biologia. O famoso "Caso Scopes" ou "O julgamento do Macaco" foi, na verdade, a caixa de ressonância do confronto entre dois pontos de vista incompatíveis. De acordo com William Martin, este caso foi um dos mais impressionantes debates envolvendo o conflito entre o intelectual e o espiritual na história dos EUA (MARTIN, 1996, p. $15)$.

${ }^{2}$ Disponível em: <http://law2.umkc.edu/faculty/projects/ftrials/scopes/tennstart.htm>. Acesso em: 7 ago. 2014. 
O caso Scopes foi levado a julgamento em julho de 1925. Para sua defesa foi enviada, pela American Civil Liberties Union (ACLU), uma equipe de advogados liderados pelo racionalista Clarence Darrow. John Scopes foi condenado e logo depois liberado sob pagamento de fiança feito pela própria ACLU.3 Scopes foi derrotado no tribunal, mas o grande vitorioso foi a ciência moderna.

Como indica Gerald Priest, o ponto central da controvérsia fundamentalistamodernista no Caso Scopes, que se deu entre o fundamentalista Bryan, advogado de acusação, e o liberal Clarence Darrow, advogado de defesa contratado pela ACLU, foi a defesa da liberdade acadêmica no ensino da ciência moderna, levada a cabo por Darrow, contra a defesa do direito dos pais de controlar o conteúdo do ensino ministrado aos seus filhos nas escolas públicas, mantidas pelos impostos pagos pela comunidade de pais, levada a cabo por Bryan (PRIEST, 1999, p. 56). Mas para os fundamentalistas esse caso representou muito mais que isso. Na opinião de Riley,

Esta batalha não foi uma guerra de palavras, nem uma pequena demonstração acerca da questão da liberdade, nem mesmo uma disputa entre cientistas de um lado e teólogos de outro, mas sim uma alegação de falsidade contra a verdade, de fé versus ateísmo, do cristianismo contra a brutalidade. (RILEY, 1925, p. 35 apud PRIEST, 1999, p. 63).

Segundo Douglas O. Linder, no confronto estabelecido no verão de 1925 no tribunal de Dayton, o que estava em jogo não era tanto a decisão acerca do destino de John Scopes, professor de biologia do ensino médio acusado de ensinar ilegalmente a teoria da evolução. E mesmo a constitucionalidade da lei antievolução do Tennesse, pouco importava naquele momento. Mas o que estava em jogo de fato era justamente a decisão sobre quem dominaria a cultura norteamericana: os modernistas ou os tradicionalistas? Assim sendo, conclui Linder, o sentido do julgamento emergiu através de sua interpretação como um conflito de valores sociais e intelectuais (LINDER, 2010).

\footnotetext{
${ }^{3}$ De acordo com Phillip E. Johnson (2008, p. 16), o advogado de John Scopes admitiu a culpa de seu cliente e pagou uma multa de US\$ 100.
} 
Para George Marsden, o julgamento de Scopes foi um evento que culminou por promover o fundamentalismo dando a ele uma atenção mundial, mas que ao mesmo tempo provocou o seu paulatino declínio como uma força nacional efetiva naquela época. Mesmo com o resultado do julgamento favorável à acusação, prevalecendo o que estava disposto na lei, os fundamentalistas, uma vez caricaturados pela imprensa como "caipiras" e "incultos", acabaram por perder parte de sua credibilidade. Sem dúvida, esse fato criou dificuldades para o movimento fundamentalista prosseguir articulando suas perspectivas mais sérias. Assim sendo, após 1925 os fundamentalistas tiveram dificuldades em ganhar novamente a atenção da opinião pública nacional (MARSDEN, 1991, p. 60). E não apenas isso. Segundo Marsden, no embate criacionismo-evolucionismo da década de 1920, a autoridade bíblica perdeu para a autonomia intelectual do fazer científico, mesmo com todos os esforços de Bryan e do movimento fundamentalista em buscar, através da arena pública e política, uma nova aliança entre a ciência moderna e a revelação bíblica (MARSDEN, 1982, p. 94).

Como nos lembra Karen Armstrong, a partir deste evento os fundamentalistas foram sistematicamente ridicularizados pela grande imprensa norte-americana, sendo considerados como "flagelo da nação", pois que "pertenciam ao passado; eram inimigos da ciência e da liberdade intelectual e não podiam participar legitimamente do mundo moderno" (ARMSTRONG, 2009, p. 246). 4

Esta vitória jurídica com gosto de derrota intelectual fez com que os fundamentalistas saíssem paulatinamente de cena pública e confessional, perdendo espaço para os teólogos liberais que, então, assumiram o controle de suas congregações. Amargurados e profundamente ressentidos com a cultura

\footnotetext{
${ }^{4}$ Apesar de tudo isso, houve um desaparecimento - quase que completo - da evolução das salas de aulas das escolas públicas nos Estados Unidos nas décadas que seguiram. Embora nunca cumprido, o Butler Act permaneceu nos livros e não foi revogado até 1967. Segundo John B. Foster, o lançamento Soviético do satélite Sputinik em 1957 e as corridas espaciais e nucleares resultaram, finalmente, na percepção de uma crise educacional nos Estados Unidos e conduziram a um recondicionamento do ensino de ciências em particular. Isto incluiu um renovado ensino da teoria da evolução. Justamente por isso, os livros de biologia foram atualizados para as escolas de ensino médio sendo incorporadas seções sobre a evolução. Imediatamente, o movimento antievolucionista mobilizado, propôs o chamado 'criacionismo científico'. Sobre esta forma, uns poucos estados, incluindo Arkansas e Louisiana, adotaram leis que requeriam 'equal time' entre o ensino da evolução e o ensino da criação nas salas de aulas (FOSTER et al, 2008, p. 11).
} 
dominante, os fundamentalistas tornaram-se ainda mais radicais em sua postura contra o establishment secularista. Segundo Armstrong,

Antes do Caso Scopes os fundamentalistas não davam importância à teoria da evolução, e até literalistas como Charles Hodge admitiam que o mundo tem mais de 6 mil anos, independente do que diz a Bíblia. Poucos acreditavam na chamada "Ciência da Criação", que proclamava a meticulosa correção científica do Gênesis. Depois de Dayton, porém, sua mentalidade se estreitou ainda mais, prevalecendo o criacionismo e um inabalável literalismo bíblico. [...] Depois do Caso Scopes retiraram-se da arena pública, refugiando-se em suas igrejas e faculdades. Os cristãos liberais concluíram que a crise fundamentalista chegara ao fim. Ao término da II Guerra Mundial os grupos fundamentalistas pareciam marginais e insignificantes. (ARMSTRONG, 2009, p. 247 e 292).

Todavia, o fato é que o fundamentalismo nos EUA não estava desaparecendo. Na realidade, seus adeptos se refugiaram em suas próprias instituições, criadas para protegê-los das intempéries do secularismo moderno e para fortalecer sua crença.

A década de 1960 testemunhou uma retomada, ainda que tímida, do engajamento fundamentalista no espaço público norte-americano. O ponto de partida desta nova etapa foram as resoluções da Suprema Corte dos EUA que baniram o culto religioso obrigatório nas escolas públicas por considerá-lo uma violação do "muro de separação" entre religião e política concebido pelos fundadores da república federativa norte-americana.5 Momento especial deste processo, como destaca Barry Hankins, foi a derrubada de leis antievolucionistas pela Suprema Corte, como no caso Epperson versus Arkansas em 1968, que levou os adeptos do fundamentalismo a mudarem de estratégia, passando de antievolucionistas a "pró-ciência da criação" (HANKINS, 2008, p. 97). ${ }^{6}$

\footnotetext{
${ }^{5}$ Em 1962, a oração ecumênica nas escolas públicas foi derrubada por uma lei em Nova York (a decisão Engel). Em 1963, foram proibidas nas escolas públicas a leitura da Bíblia e a Oração ao Senhor (a decisão Schempp). Ver Wills (1990, p. 117).

${ }^{6} \mathrm{Em} 1928$ o Estado de Arkansas adotou um estatuto que proibia o ensino "da teoria ou doutrina que considerasse que a humanidade ascendesse ou descendesse de uma ordem inferior de animais", ou que utilizasse livros didáticos que incluíssem material sobre a evolução. Esse estatuto foi uma adaptação da lei que condenou John Scopes no Tennesse. Em 1968, no caso Epperson v. Arkansas, a Suprema Corte dos Estados Unidos invalidou o Estatuto de Arkansas de 1928 que proibia o ensino da evolução. O Tribunal de Justiça considerou o estatuto inconstitucional por considerá-lo uma tentativa de fazer avançar um ponto de vista religioso.
} 


\section{2 "Equal Time" - a Ciência da Criação e as leis de garantia de tempo balanceado entre evolucionismo e criacionismo}

Alguns analistas, tais como Ronald Numbers e François Euvé, sugerem a existência de duas fases na história do movimento criacionista nos Estados Unidos. A primeira caracteriza-se por ter sido iniciada como um debate de caráter essencialmente teológico que, como indicamos, assumiu paulatinamente uma perspectiva teológico-político sob a forma das cruzadas antievolucionistas que ocorreram nos Estados Unidos durante os anos de 1920. Já a segunda fase assumiu a forma de um debate teológico-científico.7 Esta nova fase do criacionismo coincide justamente com a emergência do movimento chamado ciência da criação. O lançamento, em 1961, do livro Genesis Flood, de autoria de Henry Morris e John Whitcomb, e a fundação do Institute for Creation Research, na década de 1970, marcam decisivamente a entrada do criacionismo num novo momento, numa nova forma de discurso sobre as relações entre ciência e religião e uma nova forma de inserção no debate público.

Além do surgimento da ciência da criação, dois outros fatores igualmente importantes contribuíram para a revivescência do criacionismo a partir da década de 1960. Em primeiro lugar, como já dissemos, temos a queda das leis antievolucionistas, em especial após o caso Epperson vs. Arkansas (339 U.S. 99 1968), no qual a Suprema Corte dos EUA declarou inconstitucional a lei estadual que considerava uma ofensa "ensinar a teoria ou a doutrina de que a humanidade ascendeu ou descendeu de uma ordem mais inferior de animais"; em segundo lugar, temos a nova orientação tática do movimento fundamentalista em recorrer às cortes judiciais com vistas a estabelecer legislação estadual, ou mesmo federal,

\footnotetext{
${ }^{7}$ Ver Numbers (1982, p. 538-542). Ver também Euvé (2009, p. 94-98).
} 
impondo tratamento igual à teoria evolucionista e ao criacionismo no ensino levado a cabo nas escolas públicas norte-americanas. ${ }^{8}$

Como afirma George Marsden, em 1981 o movimento criacionista persuadiu as legislaturas dos estados de Arkansas e Louisiana a adotar leis que concedessem um "tratamento balanceado" - balanced treatment - ao ensino da teoria da evolução e a ciência da criação, sobretudo no que se refere ao tema da origem da vida e do mundo (MARSDEN, 1991, p. 153).

Por essa razão, a Câmara Legislativa do Estado de Arkansas promulgou, em março de 1981, o Act 590 que determinava que "nos textos e nas aulas de biologia das escolas secundárias, a teoria criacionista e a teoria da evolução fossem ministradas em cargas horárias iguais". A lei especificava que o criacionismo deveria ser apresentado como teoria puramente científica, sem referência a Deus ou à Bíblia. ${ }^{9}$ No preâmbulo dessa lei, podemos ver expostos os principais objetivos desse Ato:

Um ato para exigir um tratamento equilibrado entre Ciência da Criação e Ciência da Evolução nas escolas públicas; para proteger a liberdade acadêmica fornecendo escolha aos estudantes; para assegurar a liberdade de exercício religioso; para garantir a liberdade de crença e expressão; para evitar o estabelecimento de uma religião; para proibir ensino religioso concernente às origens; para coibir a discriminação em razão das crenças criacionistas ou evolucionistas; para promover definições e esclarecimentos; para declarar as finalidades e conclusões legislativas de fato; para promover divisibilidade das disposições; para promover a

\footnotetext{
${ }^{8}$ Como nos fazem saber Paulo Abrantes e Fábio Almeida, "em 1968, uma professora de Biologia do estado de Arkansas, Susan Epperson, propôs uma ação desafiando a constitucionalidade de uma lei estadual que proibia o ensino do darwinismo em escolas públicas, ou mesmo a adoção de livro-texto que abordasse o tema". Muito embora a Suprema Corte do Estado tenha cassado a sentença de primeira instância a qual havia julgado como procedente a ação da professora por entender que a lei estadual violava a liberdade de expressão, tal como consagrada na Primeira Emenda da Constituição Federal norte-americana. Mesmo assim, Susan Epperson apelou para a Suprema Corte norte-americana que, por unanimidade, declarou inconstitucional a lei estadual. De fato, os sete juízes que julgaram a ação apontaram como fundamento central da decisão a violação do Establishment Cause, ou seja, decidiram pela inconstitucionalidade da referida lei estadual por entenderem que a mesma defendia uma doutrina religiosa como ponto de partida para negar a possibilidade de uma teoria científica no âmbito de escolas públicas (ABRANTES; ALMEIDA; 2006). Para mais informações sobre o caso Epperson versus Arkansas, ver Johnson (2008, p. 171). Ver também Epperson (1968). Segundo François Euvé (2009, p. 96), as leis antievolucionistas da primeira metade do século XX, na década de 1960 são notificadas e eventualmente declaradas inconstitucionais.

${ }^{9}$ De acordo com George Webb (1994, p. 230), o projeto de lei introduzido em 24 de fevereiro de 1981 requerendo tratamento balanceado entre ciência da criação e ciência da evolução foi rapidamente referendado pelo Comitê Judiciário. No Senado o projeto de lei foi destacado por seu caráter de equidade e de liberdade de escolha. Em 13 de março após quinze minutos de debate, o Senado aprovou o Act 590 pelo voto de vinte dois a dois (WEBB, 1994, p. 230).
} 
revogação das leis contrárias; e para enunciar uma data de vigência, fica deliberado pela Assembleia Geral do Estado de Arkansas [...].10

Segundo Phillip Johnson, a lei de Louisiana de 1981 que garantia o tratamento balanceado entre o ensino da "ciência da evolução" e da "ciência da criação" nas escolas públicas, bem como leis semelhantes, elaboradas em outros estados da federação norte-americana, surgiram dos esforços de muitos anos dos cristãos fundamentalistas em reafirmar a vitalidade científica da narrativa bíblica da criação contra sua rival darwinista. E não apenas isso: "Os cientistas da criação", escreve Johnson, "argumentavam também que o ensino da evolução em si tinha um objetivo religioso, isto é, desacreditar a ideia de que um ser sobrenatural criou a humanidade" (JOHNSON, 2008, p. 16 e 19).

Entretanto, os oponentes da ciência da criação moveram uma ação na corte federal local para que a lei do Estado de Arkansas fosse declarada inconstitucional. ${ }_{11}$ Ao contrário do julgamento Scopes em 1925, no Tennessee, o tribunal de Arkansas ouviu o depoimento de grande número de testemunhas de ambos os lados. O juiz federal William Overton, que julgou o caso, decidiu em favor dos queixosos, sendo do parecer que a ciência da criação não preenchia os critérios essenciais de uma ciência porque apela para o sobrenatural e, portanto, não é testável, falsificável ou explanadora no que se refere à lei natural. ${ }^{12}$ Assim sendo, o Act 590 foi considerado inconstitucional (JOHNSON, 2008, p. 118).

Ainda que a lei de Arkansas tenha sido declarada inconstitucional na Corte do Distrito Federal e a lei estadual de Louisiana tenha sido derrubada pela Suprema Corte dos EUA, de alguma maneira tais eventos significaram um retorno

\footnotetext{
${ }^{10}$ Sobre o conteúdo do Act 590 de 1981 do Estado de Arkansas, ver: McLean (1981).

${ }^{11}$ De acordo com Paulo Abrantes e Fábio Almeida, em dezembro de 1981, a ACLU (American Civil Liberties Union) propôs uma ação judicial contra o Estado de Arkansas. A acusação pressupunha que a "ciência criacionista" não passava de discurso religioso travestido de ciência (ABRANTES; ALMEIDA, 2006, p. 368).

12 De acordo com a National Academy of Science (NAS), a ciência é concebida como um caminho particular de conhecimento sobre o mundo. Ela baseia-se em evidências empíricas e consiste na observação de fenômenos estritamente naturais. Ver: Science and Creationism: a view from the National Academy of Sciences, 1999, p. 1.
} 
organizado do criacionismo ao cenário cultural e público norte-americano. ${ }^{13}$ Todavia, a tática dos criacionistas agora, diferente daquela dos fundamentalistas da década de 1920, não era ir contra o ensino do evolucionismo, mas, sim, lutar pelo reconhecimento jurídico do criacionismo enquanto "ciência" e pelo estabelecimento igualitário do tempo dedicado ao ensino da ciência criacionista e aquele dedicado ao ensino da teoria evolucionista nas escolas públicas norteamericanas.

\section{Design Inteligente e sua tentativa de se firmar como uma legítima alternativa científica ao paradigma neodarwinista}

A teoria do design inteligente (TDI) é uma teoria alternativa e oposta à teoria da evolução. Alguns de seus críticos afirmam que ela é uma versão reelaborada do criacionismo, que teve início após a Suprema Corte dos Estados Unidos vetar o ensino do criacionismo em 1987, no caso Edwards v. Aguillard. ${ }^{14}$ Entretanto, seus proponentes e adeptos afirmam ser ela um legítimo "programa de pesquisa científica que investiga os efeitos de causas inteligentes; um movimento intelectual que desafia o darwinismo e seu legado naturalista; e um caminho para o entendimento da ação divina" (DEMBSKI, 1999, p. 13). Além disso, afirmam também que "o design inteligente é o campo de estudo que investiga sinais de inteligência". Essa teoria se propõe a "identificar as características de objetos que indicam de forma confiável a ação de uma causa inteligente" (DEMBSKI, 2005, p. 2).

Segundo o biólogo norte-americano Kenneth R. Miller, a batalha fundamental na "guerra" do Design Inteligente contra a evolução começou, quase que acidentalmente. Em 2004 o departamento de ciências da Dover Area High School em Dover, Pennsylvania, permitiu a escolha de novos livros para as suas

\footnotetext{
${ }^{13}$ Como nos faz saber lan Barbour (2004, p. 30-31), “em 1982, a Corte Federal local derrubou a lei de Arkansas, sobretudo porque ela favorecia uma visão religiosa específica, violando a separação constitucional entre igreja e estado. [...] Em 1987, a Suprema Corte dos Estados Unidos derrubou uma lei criacionista da Louisiana, afirmando que essa lei teria restringido a liberdade acadêmica e beneficiando um ponto de vista religioso específico".

${ }^{14}$ Barbara Forrest (2007, p. 7), uma das principais críticas do movimento do Design Inteligente é clara ao relacionar a origem da TDI com a derrubada da lei que garantia tratamento balanceado entre o ensino da ciência da criação e da ciência da evolução nas escolas públicas.
} 
aulas gerais de biologia. Eles escolheram um livro publicado pela Prentice Hall chamado Biologia, escrito por Kenneth Miller e Joseph Levine. O primeiro sinal de problema veio quando os membros do Conselho de Educação de Dover recusaramse a aprovar o referido livro didático. Um dos membros do Conselho se queixou de que o livro foi, em suas palavras, "atado com o darwinismo do começo ao fim", e ofereceu ajuda para apresentar uma alternativa para os professores. O Conselho também providenciou a compra de dois conjuntos de livros do Design Inteligente chamado de Pandas and People, que foram colocados na biblioteca da escola. $\mathrm{O}$ que se seguiu levaria a um julgamento da Primeira Emenda do Constituição norteamericana sobre as questões da evolução e do design inteligente chamando a atenção da imprensa do mundo inteiro para a pequena cidade de Dover e para a contínua batalha sobre o ensino de ciências nos Estados Unidos (MILLER, 2009, p. $60)$.

Em 14 de dezembro de 2004, um grupo de onze pais de estudantes do distrito escolar de Dover entrou com uma ação no tribunal federal, alegando que o Conselho de Educação de Dover havia violado seus direitos constitucionais. Kitzmiller $v$. Dover, como o processo ficou conhecido, acusou que, o conselho escolar, usando o poder de governo para trazer a ideia do Design Inteligente para as salas de aula das escolas públicas, havia, com efeito, estabelecido uma religião e consequentemente havia também violado a Primeira Emenda da Constituição. O caso se moveu para o julgamento com uma impressionante velocidade e, em 25 de setembro de 2005, o juiz John E. Jones III convocou ambas as partes à ordem de um tribunal federal em Harrisburg, Pennsylvania. O próprio Kenneth R. Miller, foi convocado como testemunha de peso para os demandantes e passou grande parte dos dois primeiros dias do julgamento no banco das testemunhas, tornando o caso para a evolução e sendo interrogado pelos advogados que defendiam o conselho escolar (MILLER, 2009, p. 61).

Além do biólogo Kenneth R. Miller, outros especialistas foram convocados pelo Juiz John E. Jones III, dentre os quais destacam-se: Michael Behe, Steve Fuller, Barbara Forrest e John Haught. 
Desta lista, como um dos principais teóricos e apoiadores do Design Inteligente, temos o bioquímico Michael Behe, autor do conhecido livro Darwin's Black Box, 1996, quem em seu testemunho buscou separar a Teoria do Design Inteligente da religião, afirmando que o design inteligente está fundado em evidências empíricas e procurando demonstrar que a “complexidade irredutível” só poderia mesmo ser atribuída a um design inteligente. ${ }^{15}$ Entretanto, como observa John B. Foster, no interrogatório Behe teve que admitir que não existia nem mesmo uma única publicação revisada (peer-reviewed) dentro da ciência para apoiar sua perspectiva de sistemas biológicos irredutivelmente complexos que não seriam possível de ser contabilizada pela evolução (FOSTER, et. al., 2008, p. 15). ${ }^{16}$

No lado da evolução, foi convocada a filósofa Barbara Forrest, coautora do livro Creationism's Trojan Horse: The Wedge of Intelligent Design, 2004, quem teria fornecido provas contundentes no tribunal de como o design inteligente era apenas um criacionismo disfarçado.

O teólogo católico da Georgetown University, John Haught, foi outro a testemunhar a favor da evolução, demonstrando em seu testemunho que os argumentos do design inteligente não são novos, mas remontam aos tempos de Tomás de Aquino e que foi mais notavelmente defendido pela teologia natural de William Paley no início do século XIX.

Assim sendo, apesar de todo o esforço de seus proponentes para promover a TDI como uma legítima alternativa à ciência moderna naturalista e à teoria darwiniana ensinadas nas aulas de ciência das escolas públicas, tendo inclusive

\footnotetext{
${ }^{15}$ Por complexidade irredutível Michael Behe entende "um sistema único composto de várias partes compatíveis, que interagem entre si e que contribuem para sua função básica, caso em que a remoção de uma das partes faria com que o sistema deixasse de funci onar de forma eficiente. Um sistema irredutivelmente complexo não pode ser produzido diretamente (isto é, pelo melhoramento contínuo da função inicial, que continua a atuar através do mesmo mecanismo) mediante modificações leves, sucessivas, de um sistema precursor, porque qualquer precursor de um sistema irredutivelmente complexo ao qual falte uma parte é, por definição, não funcional" (BEHE, 1997, p. 48). Partindo desse conceito, Behe argumenta, então, que existe uma limitação da teoria darwiniana para explicar a base molecular da vida, pois no seu entendimento nenhum processo bioquímico complexo pode ser explicado por meio dos postulados darwinianos. Isto significa que nenhum sistema bioquímico complexo poderia ser formado de maneira gradual (BEHE, 1997, p. 190). Como alternativa ao gradualismo darwiniano, Behe propõe a tese segundo a qual muitos sistemas bioquímicos foram "desenhados não por leis da natureza, pelo acaso ou pela necessidade, na verdade foram planejados. O planejador sabia qual aparência os sistemas teriam quando completos e tomou medidas para torná-los realidade em seguida. A vida na terra, em seu nível mais fundamental, em seus componentes mais importantes, é produto de atividade inteligente" (BEHE, 1997, p. 195).

${ }^{16}$ Outro especialista convocado foi o sociólogo e filósofo da ciência Steve Fuller, o qual também testemunhou a favor do Design Inteligente.
} 
recebido o apoio do então presidente dos EUA, George Bush, o qual afirmou que o design inteligente deveria ser ensinado nos currículos escolares ao lado da evolução como teorias concorrentes, ${ }^{17}$ o fato é que, no julgamento que se seguiu, o juiz federal dos EUA, John E. Jones III, no Caso Tammy Kitzmiller et al v. Dover Area School District et al, avaliou que "a esmagadora quantidade de evidências apresentada durante o julgamento estabeleceu que o design inteligente é uma perspectiva religiosa, o criacionismo com novo rótulo, e não uma teoria científica”.

O parecer do Juiz Jones se deu, principalmente, por ele reconhecer que "os escritos dos líderes e proponentes do design inteligente revelam que o designer postulado por seus argumentos é o Deus do cristianismo" - razão pela qual o ensino da TDI nas escolas públicas foi considerado inconstitucional nos termos da Cláusula de Estabelecimento da Primeira Emenda da Constituição dos Estados Unidos e do Art. I, §3 da Constituição da Pensilvânia. ${ }^{18}$ Como indica o pesquisador canadense Steven Engler, assim como acontecera com o criacionismo científico em 1987 (Edwards v. Arkansas, 482 U.S. 578), “o avanço desse novo criacionismo foi bloqueado pelos tribunais estadunidenses” (ENGLER, 2011, p. 238).

\section{Conclusão}

Após apresentarmos, ainda que brevemente, os principais casos que envolveram os debates entre criação e evolução no âmbito dos tribunais norteamericanos nestes quase cem anos de intenso conflito, gostaríamos de chamar a atenção para duas questões que julgamos importantes.

Em primeiro lugar, vale notar que esses conflitos jurídicos constituem um dos muitos exemplos do processo de deslocamento do ponto de aplicação da religião que perde seu lugar de exclusiva reserva de sentido válida a orientar a vida dos indivíduos e a explicar a realidade das coisas.

\footnotetext{
${ }^{17}$ Ver Baker; Slevin (2005).

${ }^{18}$ Kitzmiller et al v. Dover Area School District et al (400 F. Sup. 2d 707, Docket no 4cv2688), p. 43 e 3. Disponível em: <http://www.pamd.uscourts.gov/kitzmiller/kitzmiller_342.pdf>. Acesso em: 20 jul. 2011. Para maiores informações sobre o caso Kitzmiller et al v. Dover Area School District et al, ver Numbers (2006, p. 391-394) e Irons (2007, p. 59-87).
} 
Em nossa avaliação, a partir do renascimento, da reforma protestante e principalmente das Revoluções Francesa, Industrial e Científica observa-se com maior clareza uma progressiva redução da alteridade, isto é, o distanciamento de Deus da esfera pública, para dar lugar à autonomia da esfera jurídica, política, econômica, intelectual e científica. Desde então, a teologia cristã no ocidente deixa de ser gradativamente a explicação soberana sobre a existência dos seres e do universo para se tornar apenas uma reserva de sentido dentre outras de matriz não religiosa.

Sabemos, todavia, que isto não significa o desaparecimento de qualquer experiência do tipo religioso, mas sim, a emergência de uma concepção de organização da realidade social que não se funda mais no ponto de vista do Outro Absoluto. Assim sendo, como assinala o filósofo francês Marcel Gauchet, "a sociedade moderna não é uma sociedade sem religião, é uma sociedade que se constitui em suas articulações principais pelo metabolismo da função religiosa” (GAUCHET, 2005, p. 232). ${ }^{19}$

Esse deslocamento do ponto de aplicação da religião pode ser evidenciado através dos diferentes julgamentos que envolveram as disputas entre criacionistas e evolucionistas desde o início do século passado nos EUA. Vale notar que ao longo dessa trajetória jurídica existem três diferentes momentos da compreensão do criacionismo e do evolucionismo no âmbito de um debate maior que envolve a compreensão e a definição dos limites da ciência e da religião.

No primeiro momento (1920), somente o criacionismo, então compreendido como uma reserva de sentido religiosa válida para a compreensão dos seres e do universo naquele momento, conforme fundamentado por determinadas tradições religiosas, em especial o judaísmo e o cristianismo, é considerado legítimo; enquanto o evolucionismo, por supostamente se opor ao relato bíblico da criação e por estar supostamente relacionado ao secularismo e ao ateísmo, foi considerado

\footnotetext{
${ }^{19}$ Segundo Peter Berger e Thomas Luckmann (2004, p. 41), "onde a modernização progrediu mais e onde a forma moderna de pluralismo está plenamente desenvolvida, as ordens de valores e as reservas de sentido não são mais propriedade comum de todos os membros da sociedade. $O$ indivíduo cresce num mundo em que não há mais valores comuns, que determinam o agir nas diferentes áreas da vida, nem uma realidade única, idêntica para todos".
} 
ilegítimo, sendo banido do currículo básico das ciências biológicas das escolas e universidades dos Estados Unidos, como vimos.

Diante da posterior queda das leis antievolucionistas, devido à compreensão de que o ensino do criacionismo nas escolas e universidades públicas estava ferindo o princípio de separação entre Igreja e Estado estabelecido na Primeira Emenda da Constituição Norte-Americana, fato este que consequentemente fez com que o ensino do criacionismo perdesse sua legitimidade, observamos um novo momento. Neste segundo momento, tanto o criacionismo - então reformulado, adotando uma "forma científica", digamos assim - quanto o evolucionismo, então já aceito pela comunidade científica como uma teoria científica plausível, são considerados legítimos.

E finalmente, o terceiro momento, onde somente o evolucionismo, o qual assume uma concepção naturalista ou materialista (neodarwinista) e, portanto, dentro dos limites da ciência, é legítimo; enquanto o criacionismo ou mesmo o design inteligente que embora alegue estar dentro dos parâmetros aceitos pelo establishment científico, - por supostamente apelar para o sobrenatural, e por isso, estar relacionado à religião - são ilegítimos.

De fato, há uma orientação do pensamento moderno e contemporâneo segundo o qual ciência e religião são dois campos de conhecimento distintos e às vezes, opostos. Como podemos observar, apesar das críticas que veem recebendo desde a segunda metade do século passado, a ciência continua tendo o primado na definição do real, no estabelecimento de verdades públicas e universais, enquanto que a religião tem sido vista como uma das várias reservas de sentido disponíveis no espaço público e acessíveis aos indivíduos enquanto recurso para a orientação de suas escolhas privadas, como já dissemos. ${ }^{20}$

\footnotetext{
${ }^{20}$ Dado os limites do presente artigo, não foi possível tratar aqui as diversas e possíveis relações entre a perspectiva criacionista e a perspectiva evolucionista. Sabemos que o embante epistemológico entre tais perscpectivas não se resume simplesmente a uma disputa entre religião (criacionismo), de um lado, e ciência (evolucionismo), do outro. De fato, muitos analistas do tema apresentam uma diversidade de propostas e teorias que buscam, por um lado, uma aproximação da teologia cristã com o evolucionismo, e por outro, buscam apresentar outras bases, não evolutivas, para explicar a complexidade da vida. Para mais informações sobre essas questões, ver: Andrade; Barbosa (2016).
} 
Em decorrência dessas transformações da compreensão bem como das funções sociopolíticas da religião e da ciência, vale notarmos, em segundo lugar, que esse cenário revela, por um lado, uma politização cada vez mais crescente da religião e por outro, uma judicialização dos conflitos e tensões que envolvem a disputa entre as concepções criacionistas e evolucionistas nos EUA.

No que diz respeito à politização da religião, é interessante observarmos a transição do debate iminentemente teológico para o debate teológico-político promovida pelos fundamentalistas/criacionistas no início do século XX em seu embate contra a perspectiva evolucionista darwinista.

Na concepção fundamentalista a teoria da evolução representava uma dupla ameaça: primeiro, à autoridade bíblica concernente ao relato da criação e, segundo, à própria sobrevivência da sociedade como um todo. De acordo com Gerald Priest, na visão do fundamentalismo da época, a teoria da evolução era diametralmente oposta ao relato bíblico da criação e, portanto, a sua aceitação significava contradizer a palavra mesma de Deus. Além disso, acreditava-se também que o evolucionismo já teria produzido uma infinidade de males sociais e morais. Muitos fundamentalistas desse período acreditavam, por exemplo, que o fato dos alemães terem seguido as considerações evolucionistas de Friedrich Nietzsche teria levado a Alemanha à Primeira Guerra Mundial. De fato, constatamos nesse período uma transformação da controvérsia criacionismo-evolucionismo em um embate que passa a ter lugar no campo da cultura pública mesma e não apenas no âmbito das denominações religiosas stricto sensu (PRIEST, 1999, p. 56). ${ }^{21}$ Nesse sentido, fica claramente evidenciado a oposição do fundamentalismo ao evolucionismo num patamar efetivamente teológico-político, se por teológico-político entendermos a "análise e crítica dos arranjos políticos (inclusive os aspectos cultural-psicológico, social e econômico) a partir de diferentes interpretações dos propósitos de Deus para com este mundo" (SCOTT; CAVANAUGH, 2007. p. 2).

\footnotetext{
${ }^{21}$ Tomamos o conceito de "cultura pública" de James D. Hunter. No entendimento deste sociólogo da cultura, diferentemente da cultura privada, a "cultura pública" consiste em símbolos e sentidos que ordenam a vida da comunidade, ou da religião, ou da nação como um todo. Nos tempos modernos o local primeiro de experiência coletiva é o Estado-Nação. Ver: Hunter (1991, p. 54).
} 
Como também pudemos observar ao longo deste breve artigo, a Primeira Emenda da Constituição Norte-Americana - aquela que trata da separação jurídico-político entre Igreja e Estado - tem sido frequentemente usada pelos críticos do criacionismo e/ou do Design Inteligente para sustentar sua posição de rechaço, bem como para impedir o ensino dessas perspectivas - entendidas como posições estritamente religiosas - e de sua permanência no currículo básico das ciências biológicas das escolas e universidades norte-americanas.

De fato, ao longo da história dos debates jurídicos em torno das discussões sobre a origem da vida em geral e do surgimento da humanidade em particular, um dos principais argumentos sustentados por seus críticos para a recusa do criacionismo é sua ligação com o discurso religioso (judaico-cristão) o que diante do estabelecimento jurídico de separação entre Igreja e Estado, tem sido um dos principais obstáculos ao criacionismo em se estabelecer como uma teoria científica alternativa ao evolucionismo darwinista.

Finalmente é importante observarmos o lugar proeminente ocupado pelas instâncias jurídicas estaduais ou federais daquele país na mediação dos conflitos entre as diferentes concepções científicas ou religiosas. Como pudemos observar ao longo deste artigo, a "palavra final" nas definições do que pode ser considerada religião ou ciência acaba sendo finalmente dita pelos magistrados.

\section{REFERÊNCIAS}

ABRANTES, P.; ALMEIDA, F. P. L. Criacionismo e darwinismo confrontam-se nos tribunais... da razão e do direito. Revista Episteme, Porto Alegre, v. 11, n. 24, p. 366-367, jul/dez. 2006.

ANDRADE, R.; BARBOSA, W. Criação Divina ou Evolução: O criacionismo em debate. Saarbrucken, Deutschland: Novas Edições Acadêmicas, 2016.

ARMSTRONG, Karen. Em nome de Deus: o fundamentalismo no judaísmo, no cristianismo e no islamismo. São Paulo: Companhia das Letras, 2009. 
BAKER, Peter; SLEVIN, Peter. The Washington post: Bush remarks on 'intelligent design' theory fuel debate. 2005. Disponível em: <www.washigntonpost.com/wpdyn/content/article/2005/o8/o2/AR2005080201686.html>. Acesso em: 27 jul. 2012.

BARBOUR, Ian G. Quando a ciência encontra a religião. São Paulo: Cultrix, 2004.

BEHE, Michael. A caixa preta de Darwin: o desafio da bioquímica à teoria da evolução. Rio de Janeiro: Jorge Zahar, 1997.

BERGER, Peter L.; LUCKMANN, Thomas. Modernidade, pluralismo e crise de sentido: a orientação do homem moderno. Petrópolis: Vozes, 2004.

DEMBSKI, William A. In defense of intelligent design. Kentucky: Southern Baptist Theological Seminary, 2005.

DEMBSKI, William A. Intelligent design: the bridge between science \& theology. Downers Grove: IVP Academic, 1999.

DEMBSKI, William A. Why president Bush got it right about intelligent design. In: HANKINS, Barry. Evangelicalism and fundamentalism. New York: University, 2008. ELIOT, Charles O. The future of religion. Cambridge: Harvard Theological Review, 1909.

ENGLER, Steven. O criacionismo. In: Eduardo CRUZ. Teologia e ciências naturais: teologia da criação, ciência e tecnologia em diálogo. São Paulo: Paulinas, 2011.

EPPERSON, Susan et al. Appellants, v. Arkansas, n. 7. Supreme Court of the United States. Argued Oct. 16, 1968. Decided Nov. 12, 1968. Disponível em:

<http://law2.umkc.edu/faculty/projects/ftrials/conlaw/epperso.htm>. Acesso em: o8 fev. 2011.

EUVÉ, François. Darwin et le christianisme, vrais et faux débats. Paris: Buchet Chastel, 2009.

FORREST, Bárbara. Understanding the intelligent design creationist movement. Washington D.C.: Centre for Inquiry, 2007. Disponível em: <http://www.centerforinquiry.net/uploads/attachments/intelligent-design.pdf>. Acesso em: 07 jul. 2011.

FOSTER, John Bellamy; CLARK, Brett; YORK, Richard. Critique of intelligent design: materialism versus creationism from antiquity to the present. New York: Monthly Review Press, 2008.

GAUCHET, Marcel. El desencantamiento del mundo: una história política de la religión. Madri: Trotta, 2005.

HANKINS, Barry. Evangelicalism and fundamentalism, a documentary reader. New York: New York University, 2008. 
HUNTER, James Davison. Culture wars: the struggle to define America. New York: Basic Books, 1991.

IRONS, Peter. Disaster in Dover: the trials (and tribulations) of intelligent design.

Montana Law Review, Whitehall, v. 68, n. 1, 2007.

JOHNSON, Phillip E. Darwin no banco dos réus. São Paulo: Cultura Cristã, 2008.

LINDER, Douglas. An introduction to the John Scopes (monkey) trial. 2010. Disponível em: <http://law2.umkc.edu/faculty/projects/ftrials/scopes/evolut.htm>. Acesso em: 7 ago. 2014 .

MARSDEN, George M. Everyone one's own interpreter? The Bible, science, and authority in mid-nineteenth-century America. In: HATCH, Nathan O.; NOLL, Mark A. The Bible in America: essays in cultural history. New York: Oxford University Press, 1982.

MARSDEN, George M. Understanting fundamentalism and evangelicalism. Michigan: William B. Eerdmans Publishing Company, 1991.

MARTIN, William. With God on our side: the rise of the religious right in America. New York: Broadway Books, 1996.

MCLEAN V. ARKANSAS DOCUMENTATION PROJECT. State of Arkansas, 73rd General Assembly, Regular Session, 1981. Act 590 of 1981. Disponível em:

<http://www.antievolution.org/projects/mclean/new_site/legal/act_59o.htm>. Acesso em: 09 mar. 2011.

MILLER, Kenneth R. Darwin, God, and dover: what the collapse of 'intelligent design' means for science and faith in America. In: ATTRIDGE, Harold W. (Ed.). The religion and science debate: why does it continue? New Haven: Yale University Press, 2009.

NUMBERS, Ronald L. Creationism in $20^{\text {th }}$-century America. Science, Washington, v. 218, n. 4572, p. 528-544, nov. 1982. Disponível em:

<http://www.kean.edu/ bregal/docs/Darwin/RonNumbers.pdf> Acesso em: 20 dez. 2010.

NUMBERS, Ronald L. The creationists: from scientific creationism to intelligent design. Cambridge: Harvard University Press, 2006.

PRIEST, Gerald L. William Jennings Bryan and the scopes trial: a fundamentalist perspective. Detroit Baptist Seminary Journal, Allen Park, v. 4, p. 51-83, fall 1999.

RILEY, William B. The menace of modernism. New York: Alliance Publishing, 1917.

RILEY, William B. The World's Christian Fundamentals Association and the Scopes Trial. Christian Fundamentals in School and Church 7 (July, August, September 1925). 
SCIENCE AND CREATIONISM: a view from the National Academy of Sciences. Second Edition, 1999. Disponível em:

<http://www.nap.edu/openbook.php?record_id=6024\&page=1\#p200064869970001001 >. Acesso em: 29 set. 2010.

SCOTT, Peter e CAVANAUGH, Wallace (eds.). The Blackwell Companion to Political Theology. Oxford: Ed. Blackwell Publishing, 2007.

WEBB, George. The evolution controversy in America. Lexington: University of Kentucky Press, 1994.

WILLS, Garry. Under God: religion and American politics. New York: Simon and Schuster, 1990. 